\title{
Spinal Cord Stimulation in Failed Back Surgery Syndrome: Review of Clinical Use, Quality of Life and Cost-Effectiveness
}

\author{
Przemyslaw M. Waszak ${ }^{1}$, Marta Modrić ${ }^{2}$, Agnieszka Paturej ${ }^{3}$, Stanislav M. Malyshev ${ }^{4}$, \\ Agnieszka Przygocka ${ }^{5}$, Hanna Garnier ${ }^{6}$, Tomasz Szmuda ${ }^{7}$ \\ ${ }^{1} J a n u s z$ Korczak Memorial Voivodeship Hospital, Stupsk, Poland \\ ${ }^{2}$ Varaždin General Hospital, Varaždin, Croatia \\ ${ }^{3}$ Students' Scientific Association, Department of Neurosurgery, Medical University of Gdansk, Gdansk, Poland \\ ${ }^{4}$ Federal Almazov North-West Medical Research Centre, St. Petersburg, Russia \\ ${ }^{5}$ Poznań University of Medical Sciences, Poznań, Poland \\ ${ }^{6}$ Medical University of Gdansk, Gdansk, Poland \\ ${ }^{7}$ Department of Neurosurgery, Medical University of Gdansk, Gdansk, Poland
}

Failed back surgery syndrome (FBSS) is complex and recurrent chronic pain after spinal surgery. Several important patient and surgery related risk factors play roles in development of FBSS. Inadequate selection of the candidates for the spinal surgeries is one of the most crucial causes. The guidelines suggest that conservative management featuring pharmacologic approaches and rehabilitation should be introduced first. For therapy-refractory FBSS, spinal cord stimulation (SCS) is recommended in selected patients. Treatment efficacy for FBSS has increased over the years with the majority of patients experiencing pain relief and reduced medicinal load. Improved quality of life can also be achieved using SCS. Cost-effectiveness of SCS still remains unclear. However evidence for SCS role in FBSS is controversial, SCS can be beneficial for carefully classified patients.

Keywords: Spinal cord stimulation; Failed back surgery syndrome; Low back pain; Pain management

\section{Introduction}

Failed back surgery syndrome (FBSS) is a chronic pain condition that features persistent or recurring low back pain after one or more spinal surgeries [1]. In general, the term FBSS is used mainly to describe patients with ongoing pain after surgery of the lumbar spine for degenerative disc disease [2]. The pain may radiate to the lower limbs [2]. Furthermore, there is no indication of macroscopic pathology that could justify a reoperation [3]. Recent studies have revealed that FBSS patients experience greater levels of pain, lower quality of life, greater disability and higher rate of unemployment, with a significant economic impact $[4,5]$.

\section{Search Strategy and Selection Criteria}

Ebsco, Springer, Medline, PubMed, and Scopus databases were searched for journal articles using keywords "failed back surgery syndrome" AND "spinal cord stimulation."

Received Jan 29, 2016; Accepted Feb 15, 2016

Corresponding author: Przemyslaw M. Waszak

Janusz Korczak Memorial Voivodeship Hospital in Słupsk, ul. Prof. Lotha 26; 76-200 Słupsk, Poland

Tel: +48-663-534-485, E-mail: p.waszak@gumed.edu.pl 
Table 1. Etiology of failed back surgery syndrome

\begin{tabular}{|c|c|c|}
\hline Factors & Patient & Surgery \\
\hline \multirow[t]{3}{*}{ Preoperative factors } & $\begin{array}{l}\text { Psychological: anxiety, depression, } \\
\text { poor coping strategies, hypochondriasis }\end{array}$ & $\begin{array}{l}\text { Revision surgery ( } 50 \% \text { increase of the risk of spinal } \\
\text { instability) }\end{array}$ \\
\hline & Social: litigation, worker compensation & $\begin{array}{l}\text { Candidate selection (e.g., microdiscectomy } \\
\text { for axial pain) }\end{array}$ \\
\hline & - & $\begin{array}{l}\text { Surgery selection (e.g., inadequate } \\
\text { decompression in multilevel pathology) }\end{array}$ \\
\hline \multirow[t]{3}{*}{ Intraoperative factors } & - & $\begin{array}{l}\text { Poor technique (e.g., inadequate lateral recess } \\
\text { decompression, misplaced screw) }\end{array}$ \\
\hline & - & Incorrect level of surgery \\
\hline & - & $\begin{array}{l}\text { Inability to achieve the aim of surgery (e.g., far } \\
\text { lateral discectomy) }\end{array}$ \\
\hline \multirow[t]{5}{*}{ Postoperative factors } & \multicolumn{2}{|c|}{ Progressive disease (e.g., recent disc herniation, spondylolisthesis) } \\
\hline & \multicolumn{2}{|c|}{ Epidural fibrosis (tethering effect, jeopardizing nutrition, and vascular supply to nerve root) } \\
\hline & \multicolumn{2}{|c|}{ Surgical complications (e.g., nerve injury, infection, and hematoma) } \\
\hline & \multicolumn{2}{|c|}{ New spinal instability (e.g., vertical stenosis) } \\
\hline & \multicolumn{2}{|l|}{ Myofascial pain development } \\
\hline
\end{tabular}

Adopted from Chan and Peng. Pain Med 2011;12:577-606 [13].

There were more than 400 papers including these phrases. The number of articles has been constantly rising since 2010. Most ( $\mathrm{n}=182)$ came from the United States (based on Scopus). Decision of article selection was based on PRISMA statement checklist. Reports on FBSS and spinal cord stimulation (SCS) needed to have a rigid protocol, inclusion criteria and follow-up strategy. There were two randomized controlled trials (RCTs) and about 70 observational studies among the included articles.

\section{Epidemiology}

Although the surgical techniques have been continuously refined, the failure rates of spinal surgeries have not decreased. While spine surgery rates are increasing, the number of FBSS procedures has increased accordingly and has become a serious problem [6-8]. The risk of developing FBSS after lumbar spinal surgery varies from $4 \%$ to $50 \%$ [9-12]. The wide range reflects the heterogeneities in the study populations, criteria, procedures, follow-up duration and historical timing of the surgery. All of these issues indicate the need for further research to better understand the etiology of FBSS [5]. The current frequency of this syndrome in the general population is estimated as $0.02 \%$ and $2 \%$ [9-12].

\section{Pathophysiology}

The etiology of FBSS can be divided into three groups: preoperative, intraoperative, and postoperative (Table 1) [13]. Inadequate selection of the candidates for the spinal surgeries is one of the most crucial causes of FBSS [14]. In many cases the primary low back pain resolves spontaneously and wrongly commissioned early surgical intervention may expose patients to the risk of the further long-lasting complications [15]. Therefore a significant proportion of the increasing number of spinal surgeries might be unnecessary [16]. A study in the United States demonstrated that the areas with the lowest surgical rates achieved the best outcomes, with the worst results occurring in the areas with the highest surgical rates [17]. The rate of spinal surgery in the United States is at least $40 \%$ higher than in any other country [18]. It highlights the great importance of careful selection of the spinal surgery candidates. Other important causes of FBSS mentioned in the literature are poor diagnostic evaluation leading to inappropriate treatment, inadequate surgery and intraoperative damage to the nerve roots $[19,20]$.

\section{Diagnosis}

A detailed clinical history regarding spinal pain and its 
previous management (both surgical and conservative) should be obtained by a physician. A careful interview with the patient can also highlight possible secondary causes of the pain problems, such as other medical conditions and behavioral reactions. Full neurologic examination of involved areas should be performed beforehand to exclude a potential surgical emergency (e.g., motor defect). Magnetic resonance imaging is the imaging modality of choice for patients with FBSS. Conditions like pondyloarthropathies, spinal neoplasms, infection, sequestrated fragment, scar or fibrosis formation, recurrent disc herniation, stenosis or instability should be excluded before establishing FBSS diagnosis [14].

\section{Management}

The nature of FBSS is complex as it involves both neuropathic and nociceptive elements. Treatment is challenging [21]. Healthcare providers have established many management options. Evidence-based guidelines have been published to aid in selection of the best treatment [22-24]. The guidelines recommend initial conservative management. Concerning pharmacological options, oral amitriptyline, gabapentin, or pregabalin are the suggested firstline treatments for neuropathic pain [24].

In the case of chronic low back pain, guidelines recommend interdisciplinary rehabilitation with a cognitive and behavioral emphasis [22]. A prospective study compared the interdisciplinary treatment response between non-FBSS and FBSS patients [25]. Improvement in pain and functional level was evident for both groups. When management is unsatisfactory, further steps may be considered; these include epidural corticosteroid administration, pulsed radiofrequency treatment, and percutaneous epidural adhesiolysis [26-28].

In most cases, another surgery is not indicated as the success rate declines after subsequent procedures and only $20 \%-30 \%$ of the repeated lumbosacral operations are effective $[1,29]$. Surgery is recommended only in the presence of detectable neurological lesion that is amenable to a surgical procedure [30].

Regarding therapy-refractory FBSS where the implemented conservative treatment did not achieve adequate pain relief, SCS is strongly recommended [27]. FBSS is currently the most common indication for SCS in the United States [31]. It is generally considered as one of the last resorts in the pain management algorithm $[32,33]$
(Fig. 1).

In 2008 the United Kingdom National Institute for Clinical Excellence released a guidance for SCS implementation for patients suffering from severe, prolonged pain responsive to trial stimulation in FBSS, complex regional pain syndrome (CRPS), and neuropathic pain [34]. The American Academy of Pain Medicine defined crucial assumptions for a successful screening trial, namely: 50\% or more pain relief persisting despite provocative physical therapy, stable or decreased analgesic dosage, patient satisfaction with the SCS results, and patient ability to maintain the technical aspect of the device [35]. The British Pain Society still believes that more high-quality RCTs are needed for SCS as a reliable method of treatment. Nonetheless, the society supports SCS therapy under the condition of appropriately and carefully selected patients by thoroughly prepared multidisciplinary teams. The society published recommendations for best clinical practice and the context of SCS usage; these emphasize a multidisciplinary approach to properly assess patients [34]. SCS therapy in carefully selected FBSS patients presenting mainly radicular pain, declaring a reasonable level of expectations and the need for compliance, combined with a strict cooperation with a multidisciplinary team of specialists, is likely to be the new standard of good clinical practice.

\section{Pathophysiologic background of SCS}

Electrotherapy has its beginning in 1965 when Melzack and Wall [36] proposed the gate control theory. The theory posited that nerves carrying pain stimuli and vibration and touch sensations both terminate in the dorsal horn of the spinal cord. Activation of large myelinated A-fibres can suppress the transmission of pain stimulus through the spinal integrative center (the gate) $[37,38]$.

In 1989 the U.S. Food and Drug Administration approved SCS to treat pain from nerve damage in the trunk, arms, or legs, including unilateral or bilateral pain associated with FBSS, which was defined as pain continuing or resuming despite an operative procedure undertaken to correct the cause of the pain.

\section{Device and Its Implantation}

A proposed mechanism of pain signal inhibition by SCS stimuli is shown in Fig. 2. A typical SCS device consists 


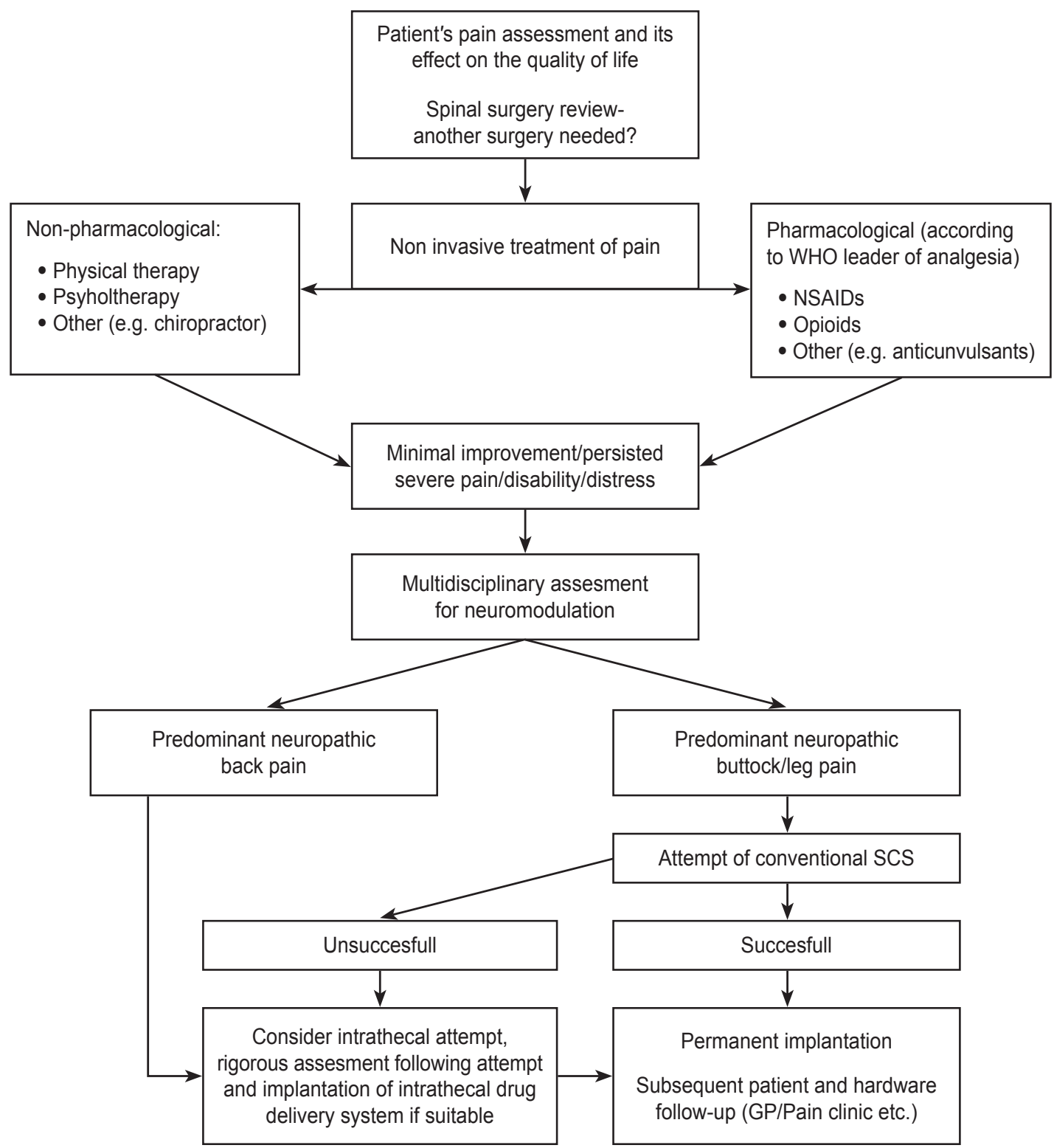

Fig. 1. Proposed management algorithm of patients with failed back surgery syndrome (based on Ganty and Sharma [33]). WHO, World Health Organization; NSAID, nonsteroidal anti-inflammatory drug; SCS, spinal cord stimulation; GP, general practitioner.

of four components: a pulse generator, a lead that connects the electrode(s) contacts to the electrical pulse generator, an extension cable that connects the lead(s) to the pulse generator, and a remote controller to turn the stimulator on or off and to adjust the level of stimulation. SCS implantation usually consists of two phases. Patient selected for SCS implantation should have a stimulation trial, using externalized leads to mimic the effects of a true neurostimulator. If the stimulation trial is successful, permanent surgical implantation of a spinal stimulator is performed.

\section{Complications}

Most studies have reported generally minor adverse effects, except for a few cases of epidural abscess, thrombosis, meningism, cerebrospinal fluid (CSF) fistula, and hemorrhage. The most common reported complication was lead migration (15\%-28\% when traditional SCS was used and $2 \%-2.5 \%$ when new SCS techniques were used), followed by local wound infection, pocket pain, loss of therapeutic effect, or CSF leak with headache [39-43]. 


\section{The spinal cord stimulation}

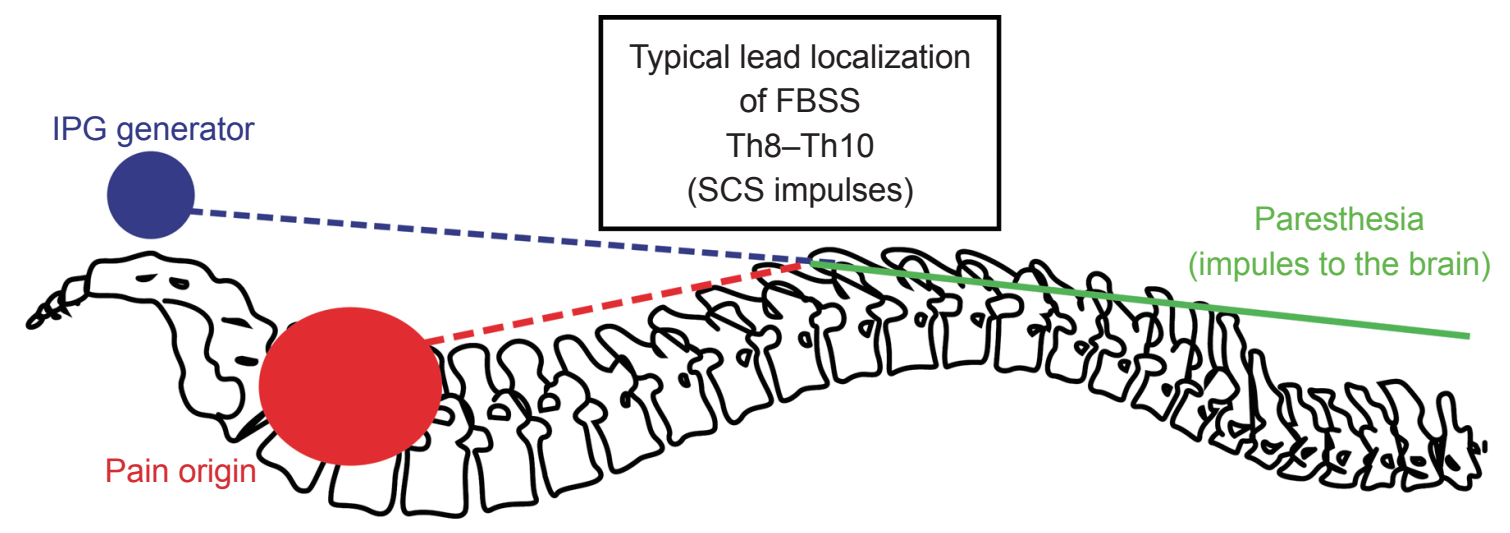

Fig. 2. Proposed traditional spinal cord stimulation physiologic mechanism based on "gate theory." IPG, implantable pulse generator; FBSS, failed back surgery syndrome; SCS, spinal cord stimulation.

\section{Evidences for SCS Effectiveness in FBSS}

Clinical studies have shown improvement of 50\% to 70\% concerning decreased dosages of analgesics, decreased pain intensity scores, and functional amelioration [44]. Although SCS declines in effectiveness over time due to the growing central nervous system tolerance in $20 \%$ to $40 \%$ of patients, still advantages outrank reoperation [45]. Literature reviews have documented an increasing treatment efficacy in FBSS with time, with pain reduced by over $50 \%$ and medical usage reduced by $41 \%$ to $84 \%$ in the majority of patients [45-47].

The RCT performed by North et al. [48] and the PROCESS trial by Kumar et al. [49] bolstered the high efficacy of SCS in FBSS treatment. North et al. [48] compared SCS patients to those who underwent a reoperation of lumbosacral spine. PROCESS compared SCS plus conventional medical management (CMM) to CMM alone. CMM consisted of oral medications, nerve blocks, epidural corticosteroids, and physical and psychological therapy [49]. North et al. [48] documented significant pain relief in $39 \%$ of the patients from the SCS group vs. $12 \%$ in the reoperation group, and confirmed an $87 \%$ decrease in analgesic use (SCS) to only $58 \%$ in reoperation group. At 6-months follow-up, the majority of patients (67\%) from the reoperation group desired to crossover to SCS therapy. The more recent PROCESS study results supported the aforementioned statistics in terms of pain management ( $>50 \%$ pain relief in $47 \%$ of SCS and $7 \%$ of CMM), but the reduction in medication dosage was unclear. Statistically significant $(p \leq 0.05)$ improvements in SCS group outcome compared to the control group at follow-up were described for satisfaction and quality of life. A 6-month follow-up revealed a $32 \%$ rate of device-related complications (Table 2) [3,13,34,38].

The benefit of SCS in FBBS treatment has been confirmed only in patients presenting radicular pain, with no efficacy evident in patients suffering from axial pain with a small radicular component $[13,48,49]$. For many patients, a single epidural SCS lead is sufficient to provide the paresthesia coverage required for pain relief in limbs. However, this is generally not the case for patients with axial low back pain. A few preliminary studies of a new dual lead SCS system concluded that it is able to provide low back and paresthesia coverage. The results were not similar to data indicating that dual stimulation does not offer advantages with respect to conventional, single electrode array stimulation $[39,50]$.

In a 2014, systematic review and meta-regression analysis, Taylor et al. [51] addressed SCS related issues in FBSS treatment. There were 74 included trials. However, data quality were poor and very heterogeneous. The mean level of pain relief across the studies was 58\% (95\% confidence interval, 53\%-64\%) during an average follow-up of 24 months. However, among the predicting factors only duration of pain was significantly related to the outcome. In fact, the longest pain duration produced the lowest magnitude of pain relief. There were only a few studies reporting the level of stimulation, therefore any quantitative analysis of the difference between back and leg pain relief was impossible [51].

The ongoing multicenter (30 neurosurgical centers) and 
Table 2. Summary of randomized control trials studying SCS effectiveness in FBSS

\begin{tabular}{|c|c|c|c|c|c|c|c|}
\hline \multicolumn{8}{|c|}{ Spinal cord stiumulation in failed back surgery syndrome } \\
\hline \multirow{2}{*}{ Study } & \multirow{2}{*}{ Country } & \multirow{2}{*}{ Comparisons } & \multicolumn{2}{|c|}{ No. of patients } & \multirow{2}{*}{ Outcomes } & \multirow{2}{*}{ Results } & \multirow{2}{*}{$\begin{array}{l}\text { CONSORT } 2010 \\
\text { RCTs checklist } \\
\text { (patients) }^{\text {a) }}\end{array}$} \\
\hline & & & SCS & Control & & & \\
\hline \multirow[t]{2}{*}{$\begin{array}{l}\text { North et al. [48], } \\
2005\end{array}$} & USA & $\begin{array}{l}\text { SCS vs. } \\
\text { reoperation }\end{array}$ & 19 & 26 & Pain relief & $\begin{array}{l}38 \% \text { of SCS vs. } 12 \% \\
\text { of control }\end{array}$ & $21(57 \%)$ \\
\hline & & & & & Analgesic use & $\begin{array}{l}\text { Decreased dosage in } \\
87 \% \text { of SCS vs. } 58 \% \text { in } \\
\text { control }\end{array}$ & \\
\hline \multirow[t]{5}{*}{$\begin{array}{l}\text { Kumar et al. [41], } \\
2008\end{array}$} & $\begin{array}{l}\text { Europe/ } \\
\text { Canada/ } \\
\text { Israel/ } \\
\text { Australia }\end{array}$ & $\begin{array}{l}\text { SCS+ CMM vs. } \\
\text { CMM alone }\end{array}$ & 42 & 41 & Pain relief & $\begin{array}{l}\text { Pain relief }>50 \% \text { in } 47 \% \\
\text { of SCS vs. } 7 \% \text { of CMM }\end{array}$ & $32(86 \%)$ \\
\hline & & & & & Analgesic use & Results uncertain & \\
\hline & & & & & $\begin{array}{l}\text { Quality of life } \\
\text { and satisfaction }\end{array}$ & $\begin{array}{l}\text { Statistically significant } \\
(p \leq 0.05) \text { improvements }\end{array}$ & \\
\hline & & & & & Work ability & $\begin{array}{l}\text { Not statistically signifi- } \\
\text { cant }(p>0.05) \text { difference }\end{array}$ & \\
\hline & & & & & Complications & $\begin{array}{l}32 \% \text { Rate of device- } \\
\text { related complications }\end{array}$ & \\
\hline
\end{tabular}

Modified from Chan and Peng. Pain Med 2011;12:577-606 [13] and The British Pain Society. Spinal cord stimulation for the management of pain: recommendations for best clinical practice (2009) [34].

SCS, spinal cord stimulation; FBSS, failed back surgery syndrome; RCT, randomized controlled trial; CMM, conventional medical management.

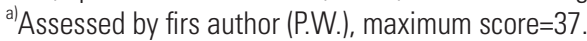

global PROMISE study (NCT01697358) is enrolling FBSS patients and randomizing them to SCS or optimal medical management groups [52].

\section{Quality of Life after SCS Implantation}

FBSS causes serious problems in terms of its social, physical, and psychological effects on the affected individuals [53]. Many studies showed statistically significant difference, measured in psycho-sociological questionnaires, between baseline and follow-up [54,55]. A systematic review of 13 studies reported improvement in physical function as measured by the Sickness Impact Profil, disability measured by the Oswestry disability index (ODI), activities of daily living, participation in leisure, social, and workrelated activities [56]. Several other studies did not show statistically significant improved ability to participate in social activities and pursue hobbies $[50,57,58]$. A reduction in physical function negatively impacts quality of life and ability to work.

As most articles recruit patients with a mean pain history of more than 5 years, return to work is not likely to happen after years of inactivity [54]. Yet, it is noteworthy that $30 \%$ of 37 employment-age patients in the 2008 PROCESS trial were working at 24 months follow-up, especially because four of the patients had been out of work for a mean of more than 2.5 years [41]. Similar results were obtained by North et al. [48]., while no significant changes were obtained by other authors who were assessing work status $[50,59,60]$.

Compared with CMM, significant improvements occurred with SCS across the ODI sub-dimensions of pain intensity, sex life, sitting, social life, standing, traveling, and walking; than across the physical component score and mental component score subcomponents of the SF-36 and dimensions of EQ-5D: anxiety/depression, pain/discomfort, self-care, and usual activities. Two sub-dimensions of ODI (personal care and sleeping) and one dimension of EQ-5D (mobility) did not improve compared with baseline [61].

\section{Cost-Effectiveness of SCS}

Chronic pain is an economic problem. In Europe, its total 
financial cost represents $3 \%-10 \%$ of its gross domestic product, including both direct and indirect costs [62]. Most of the authors emphasize that advantages of SCS become obvious in a long perspective. Whilst pharmacotherapy and other routine methods of treatment (CMM) are significantly cheaper, high expenditure on implantation of the stimulator is recompensed by decreasing of physical disability and, consequently, both direct and indirect costs.

In a Canadian study, the cost-effectiveness of CMM versus a combination of SCS and adjunctive CMM was compared using Markov models [63]. The study showed that the additional effectiveness of SCS+CMM cost CAN\$ 9,293 and 11,216 per quality-adjusted life year (QALY) gained, depending on an illness. It is considered that a medical technology is cost-effective if this parameter (incremental cost-effectiveness ratio, ICER) is lower than the societal willingness to pay per QALY. Willingness to pay (WTP) is defined as the hypothetical limits to resources that society is willing to allocate for the benefit achieved by a medical intervention. In Canada, WTP is CAN\$ 50,000, therefore, SCS can be considered to be cost-effective, even though it is more expensive in the short-term.

A systematic review of 11 small RCTs demonstrated that ICER and therefore cost-effectiveness of SCS in treatment of FBSS and CRPS type I (CRPS I) depends on device longevity and price [64]. For example, a modelbased analysis showed the cost-effectiveness of SCS for CRPS I in United Kingdom with an ICER of $£ 3562$ per QALY in a 6 months perspective [65]. Evidence against cost-effectiveness of SCS, specifically for FBSS, has been published [66]. RCTs that model routine practice may not fully represent the real effects of a technology. The authors argued that in community settings high costs of SCS are not counterbalanced by lowered CMM costs, with no evidence that the high cost of SCS was counterbalanced by lower subsequent medical costs or productivity gain

The weight of evidence indicates that SCS seems to be cost-effective, at least in the long-term. However, the existing evidence is insufficient. Most of the trials involved small numbers of samples; this is because SCS is a rare method that is in use only in some medical centers for treatment of a restricted population. Also, research on cost-effectiveness strongly depends on features of a healthcare system, so it should be conducted in different countries and different conditions.

\section{Limitations and Controversies}

Although the introduction of SCS was inspired by the Melzack gate theory, its mechanism has not been fully investigated. It is not clear how SCS works in detail [34]. If SCS action was only depended on simple gate control theory, the failure ratio would not be so high [37]. More recent papers have reported the role of several neurotransmitters (gamma-aminobutyric acid, acetylcholine, and serotonin) as well as numerous additional spinal fibers [6770]. It is not clear if the SCS mechanism acts segmentally or more widely. In one of the recent studies, rats with SCS placed directly on the damaged fibers had a better performance than rats with electrodes placed more rostrally [71]. In contrast, several functional neuroimaging studies have shown the involvement of numerous brain areas $[72,73]$.

While popular globally, SCS still lacks scientific rationale. Regardless of evidence hierarchy, the key should be the study design. The only two RCTs $[48,49]$ provided very useful data, but are not ultimately conclusive for SCS in FBSS. Reviewing these articles with a CONSORT checklist reader uncovers doubts regarding study design reporting (Table 2). Other limitations regarding these studies include patient selection, small groups, short follow-up, and exclusion of the most problematic patients from a trial. It is also worth noting that the studies of Kumar et al. [49] and North et al. [48] were supported by the medical technology companies that manufacture the SCS devices.

\section{Conclusions}

The role of SCS remains controversial, SCS can be beneficial and therefore worth considering for carefully addressed considered cases. SCS can be useful last resort treatment, which eventually can resolve chronic (mainly radicular) pain.

\section{Conflict of Interest}

No potential conflict of interest relevant to this article was reported.

\section{References}

1. North RB, Campbell JN, James CS, et al. Failed back surgery syndrome: 5-year follow-up in 102 patients 
undergoing repeated operation. Neurosurgery 1991; 28:685-90.

2. Van Buyten JP, Linderoth B. "The failed back surgery syndrome": definition and therapeutic algorithms: an update. Eur J Pain Suppl 2010;4:273-86.

3. Kumar K, Toth C. The role of spinal cord stimulation in the treatment of chronic pain postlaminectomy. Curr Rev Pain 1998;2:85-92.

4. Thomson S, Jacques L. Demographic characteristics of patients with severe neuropathic pain secondary to failed back surgery syndrome. Pain Pract 2009;9:20615.

5. Taylor RS, Taylor RJ. The economic impact of failed back surgery syndrome. Br J Pain 2012;6:174-81.

6. Mark VH. Instrumented fusions: a need for guidelines and research. Surg Neurol 2004;61:318-9.

7. Burton CV. Failed back surgery patients: the alarm bells are ringing. Surg Neurol 2006;65:5-6.

8. Talbot L. "Failed back surgery syndrome". BMJ 2003; 327:985-6.

9. Weber H. Lumbar disc herniation: a controlled, prospective study with ten years of observation. Spine (Phila Pa 1976) 1983;8:131-40.

10. Brox JI, Reikeras O, Nygaard O, et al. Lumbar instrumented fusion compared with cognitive intervention and exercises in patients with chronic back pain after previous surgery for disc herniation: a prospective randomized controlled study. Pain 2006;122:145-55.

11. Fritzell P, Hagg O, Nordwall A. Complications in lumbar fusion surgery for chronic low back pain: comparison of three surgical techniques used in a prospective randomized study: a report from the Swedish Lumbar Spine Study Group. Eur Spine J 2003;12:178-89.

12. Peul WC, van Houwelingen HC, van den Hout WB, et al. Surgery versus prolonged conservative treatment for sciatica. N Engl J Med 2007;356:2245-56.

13. Chan CW, Peng P. Failed back surgery syndrome. Pain Med 2011;12:577-606.

14. Sharma R, Sharma A, Prasher B. Review on failed back surgery syndrome. Int J Pharm Technol 2013;5: 2495-508.

15. Yadla S, Malone J, Campbell PG, et al. Early complications in spine surgery and relation to preoperative diagnosis: a single-center prospective study. J Neurosurg Spine 2010;13:360-6.

16. Epstein NE, Hood DC. "Unnecessary” spinal surgery: a prospective 1-year study of one surgeon's experience. Surg Neurol Int 2011;2:83.

17. Keller RB, Atlas SJ, Soule DN, Singer DE, Deyo RA. Relationship between rates and outcomes of operative treatment for lumbar disc herniation and spinal stenosis. J Bone Joint Surg Am 1999;81:752-62.

18. Cherkin DC, Deyo RA, Loeser JD, Bush T, Waddell G. An international comparison of back surgery rates. Spine (Phila Pa 1976) 1994;19:1201-6.

19. Waguespack A, Schofferman J, Slosar P, Reynolds J. Etiology of long-term failures of lumbar spine surgery. Pain Med 2002;3:18-22.

20. Rodrigues FF, Dozza DC, de Oliveira CR, de Castro RG. Failed back surgery syndrome: casuistic and etiology. Arq Neuropsiquiatr 2006;64:757-61.

21. Wiesenfeld-Hallin Z, Aldskogius H, Grant G, Hao JX, Hokfelt T, Xu XJ. Central inhibitory dysfunctions: mechanisms and clinical implications. Behav Brain Sci 1997;20:420-5.

22. Chou R, Loeser JD, Owens DK, et al. Interventional therapies, surgery, and interdisciplinary rehabilitation for low back pain: an evidence-based clinical practice guideline from the American Pain Society. Spine (Phila Pa 1976) 2009;34:1066-77.

23. Chou R, Huffman LH. Medications for acute and chronic low back pain: a review of the evidence for an American Pain Society/American College of Physicians clinical practice guideline. Ann Intern Med 2007;147:505-14.

24. National Institute for Health and Care Excellence. Neuropathic pain: the pharmacological management of neuropathic pain in adults in non-specialist settings. NICE guidelines 96. Manchester: National Institute for Health and Care Excellence; 2010.

25. Miller B, Gatchel RJ, Lou L, Stowell A, Robinson R, Polatin PB. Interdisciplinary treatment of failed back surgery syndrome (FBSS): a comparison of FBSS and non-FBSS patients. Pain Pract 2005;5:190-202.

26. Abdi S, Datta S, Trescot AM, et al. Epidural steroids in the management of chronic spinal pain: a systematic review. Pain Physician 2007;10:185-212.

27. Van Boxem K, Cheng J, Patijn J, et al. 11. Lumbosacral radicular pain. Pain Pract 2010;10:339-58.

28. Epter RS, Helm S 2nd, Hayek SM, Benyamin RM, Smith HS, Abdi S. Systematic review of percutaneous adhesiolysis and management of chronic low back pain in post lumbar surgery syndrome. Pain Physi- 
cian 2009;12:361-78.

29. Fritsch EW, Heisel J, Rupp S. The failed back surgery syndrome: reasons, intraoperative findings, and longterm results: a report of 182 operative treatments. Spine (Phila Pa 1976) 1996;21:626-33.

30. Deyo RA. Back surgery: who needs it? N Engl J Med 2007;356:2239-43.

31. Nagel SJ, Lempka SF, Machado AG. Percutaneous spinal cord stimulation for chronic pain: indications and patient selection. Neurosurg Clin N Am 2014;25: 723-33.

32. Demartini L, Stocco E, Bonezzi C. Failed back surgery syndrome and intrathecal drugs infusion. Eur J Pain Suppl 2010;4:299-301.

33. Ganty P, Sharma M. Failed back surgery syndrome: a suggested algorithm of care. Br J Pain 2012;6:153-61.

34. The British Pain Society. Spinal cord stimulation for the management of pain: recommendations for best clinical practice. London: The British Pain Society; 2009.

35. North R, Shipley J, Prager J, et al. Practice parameters for the use of spinal cord stimulation in the treatment of chronic neuropathic pain. Pain Med 2007;8 Suppl 4:S200-75.

36. Melzack R, Wall PD. Pain mechanisms: a new theory. Science 1965;150:971-9.

37. Meier K. Spinal cord stimulation: background and clinical application. Scand J Pain 2014;5:175-81.

38. Masopust V, Rokyta R, Benes V. Neuromodulation. Cesk Slov Neurol Neurochir 2014;77:138-52.

39. Abejon D, Reig E, Del Pozo C, Contreras R, Insausti J. Dual spinal cord stimulation for complex pain: preliminary study. Neuromodulation 2005;8:105-11.

40. de Vos CC, Dijkstra C, Lenders MW, Holsheimer J. Spinal cord stimulation with hybrid lead relieves pain in low back and legs. Neuromodulation 2012;15:11823.

41. Kumar K, Taylor RS, Jacques L, et al. The effects of spinal cord stimulation in neuropathic pain are sustained: a 24-month follow-up of the prospective randomized controlled multicenter trial of the effectiveness of spinal cord stimulation. Neurosurgery 2008; 63:762-70.

42. Liem L, Russo M, Huygen FJ, et al. One-year outcomes of spinal cord stimulation of the dorsal root ganglion in the treatment of chronic neuropathic pain. Neuromodulation 2015;18:41-8.
43. Van Buyten JP, Al-Kaisy A, Smet I, Palmisani S, Smith T. High-frequency spinal cord stimulation for the treatment of chronic back pain patients: results of a prospective multicenter European clinical study. Neuromodulation 2013;16:59-65.

44. North RB, Kidd DH, Piantadosi S. Spinal cord stimulation versus reoperation for failed back surgery syndrome: a prospective, randomized study design. Acta Neurochir Suppl 1995;64:106-8.

45. LeDoux MS, Langford KH. Spinal cord stimulation for the failed back syndrome. Spine (Phila Pa 1976) 1993;18:191-4.

46. Turner JA, Loeser JD, Bell KG. Spinal cord stimulation for chronic low back pain: a systematic literature synthesis. Neurosurgery 1995;37:1088-95.

47. Ohnmeiss DD, Rashbaum RF, Bogdanffy GM. Prospective outcome evaluation of spinal cord stimulation in patients with intractable leg pain. Spine (Phila Pa 1976) 1996;21:1344-50.

48. North RB, Kidd DH, Farrokhi F, Piantadosi SA. Spinal cord stimulation versus repeated lumbosacral spine surgery for chronic pain: a randomized, controlled trial. Neurosurgery 2005;56:98-106.

49. Kumar K, Taylor RS, Jacques L, et al. Spinal cord stimulation versus conventional medical management for neuropathic pain: a multicentre randomised controlled trial in patients with failed back surgery syndrome. Pain 2007;132:179-88.

50. Van Buyten JP, Van Zundert J, Milbouw G. Treatment of failed back surgery syndrome patients with low back and leg pain: a pilot study of a new dual lead spinal cord stimulation system. Neuromodulation 1999;2:258-65.

51. Taylor RS, Desai MJ, Rigoard P, Taylor RJ. Predictors of pain relief following spinal cord stimulation in chronic back and leg pain and failed back surgery syndrome: a systematic review and meta-regression analysis. Pain Pract 2014;14:489-505.

52. Rigoard P, Desai MJ, North RB, et al. Spinal cord stimulation for predominant low back pain in failed back surgery syndrome: study protocol for an international multicenter randomized controlled trial (PROMISE study). Trials 2013;14:376.

53. Reverberi C, Dario A, Barolat G. Spinal cord stimulation (SCS) in conjunction with peripheral nerve field stimulation (PNfS) for the treatment of complex pain in failed back surgery syndrome (FBSS). Neuromod- 
ulation 2013;16:78-82.

54. Spincemaille GH, Beersen N, Dekkers MA, Theuvenet PJ. Neuropathic limb pain and spinal cord stimulation: results of the dutch prospective study. Neuromodulation 2004;7:184-92.

55. Murthy TV, Sahoo PK. Spinal cord stimulation: advanced pain therapy for failed back surgery syndrome: our experience. J Anaesthesiol Clin Pharmacol 2009;25:337-40.

56. Kelly GA, Blake C, Power CK, O'Keeffe D, Fullen BM. The impact of spinal cord stimulation on physical function and sleep quality in individuals with failed back surgery syndrome: a systematic review. Eur J Pain 2012;16:793-802.

57. Dario A, Fortini G, Bertollo D, Bacuzzi A, Grizzetti C, Cuffari S. Treatment of failed back surgery syndrome. Neuromodulation 2001;4:105-10.

58. Turner JA, Loeser JD, Deyo RA, Sanders SB. Spinal cord stimulation for patients with failed back surgery syndrome or complex regional pain syndrome: a systematic review of effectiveness and complications. Pain 2004;108:137-47.

59. Burchiel KJ, Anderson VC, Brown FD, et al. Prospective, multicenter study of spinal cord stimulation for relief of chronic back and extremity pain. Spine (Phila Pa 1976) 1996;21:2786-94.

60. Frey ME, Manchikanti L, Benyamin RM, Schultz DM, Smith HS, Cohen SP. Spinal cord stimulation for patients with failed back surgery syndrome: a systematic review. Pain Physician 2009;12:379-97.

61. Eldabe S, Kumar K, Buchser E, Taylor RS. An analysis of the components of pain, function, and healthrelated quality of life in patients with failed back surgery syndrome treated with spinal cord stimulation or conventional medical management. Neuromodulation 2010;13:201-9.

62. Breivik H, Eisenberg E, O'Brien T. The individual and societal burden of chronic pain in Europe: the case for strategic prioritisation and action to improve knowledge and availability of appropriate care. BMC Public Health 2013;13:1229.

63. Kumar K, Rizvi S, Bnurs SB. Spinal cord stimulation is effective in management of complex regional pain syndrome I: fact or fiction. Neurosurgery 2011;69: 566-78.
64. Simpson EL, Duenas A, Holmes MW, Papaioannou D, Chilcott J. Spinal cord stimulation for chronic pain of neuropathic or ischaemic origin: systematic review and economic evaluation. Health Technol Assess 2009;13:1-154.

65. Kemler MA, Raphael JH, Bentley A, Taylor RS. The cost-effectiveness of spinal cord stimulation for complex regional pain syndrome. Value Health 2010;13: 735-42.

66. Hollingworth W, Turner JA, Welton NJ, Comstock BA, Deyo RA. Costs and cost-effectiveness of spinal cord stimulation (SCS) for failed back surgery syndrome: an observational study in a workers' compensation population. Spine (Phila Pa 1976) 2011;36: 2076-83.

67. Cui JG, Linderoth B, Meyerson BA. Effects of spinal cord stimulation on touch-evoked allodynia involve GABAergic mechanisms: an experimental study in the mononeuropathic rat. Pain 1996;66:287-95.

68. Song Z, Meyerson BA, Linderoth B. Muscarinic receptor activation potentiates the effect of spinal cord stimulation on pain-related behavior in rats with mononeuropathy. Neurosci Lett 2008;436:7-12.

69. Yang F, Carteret AF, Wacnik PW, et al. Bipolar spinal cord stimulation attenuates mechanical hypersensitivity at an intensity that activates a small portion of A-fiber afferents in spinal nerve-injured rats. Neuroscience 2011;199:470-80.

70. Song Z, Meyerson BA, Linderoth B. Spinal 5-HT receptors that contribute to the pain-relieving effects of spinal cord stimulation in a rat model of neuropathy. Pain 2011;152:1666-73.

71. Smits H, van Kleef M, Joosten EA. Spinal cord stimulation of dorsal columns in a rat model of neuropathic pain: evidence for a segmental spinal mechanism of pain relief. Pain 2012;153:177-83.

72. Kishima H, Saitoh Y, Oshino S, et al. Modulation of neuronal activity after spinal cord stimulation for neuropathic pain; H(2)15O PET study. Neuroimage 2010;49:2564-9.

73. Stancak A, Kozak J, Vrba I, et al. Functional magnetic resonance imaging of cerebral activation during spinal cord stimulation in failed back surgery syndrome patients. Eur J Pain 2008;12:137-48. 